\title{
Substratum heterogeneity and complexity influence micro-habitat selection of Balanus sp. and Tubularia crocea larvae
}

\author{
Maryse Lemire, Edwin Bourget* \\ GIROQ, Département de Biologie, Université Laval, Québec, Québec, Canada G1K 7P4
}

\begin{abstract}
This experimental study examines the importance of active and passive processes during the settlement of the barnacle Balanus sp. and the hydrozoan Tubularia crocea larvae. Three hypotheses were tested: (1) larvae of Balanus sp. and $T$ crocea exhibit settlement preferences with respect to scales of topographic heterogeneity $(0,1,10$ and $100 \mathrm{~mm} \mathrm{~V}$-shaped grooves); (2) these preferences are modified by substratum complexity (combinations of scales of topographic heterogeneity); and (3) these preferences are mediated by larval behaviour directly on or near the substratum (benthic behaviour: after initial contact with the substratum). Artificial PVC panels of different scales of heterogeneity and complexity were submerged $30 \mathrm{~cm}$ below the surface during autumn 1992, at Beaufort, North Carolina, USA. A comparison between the final attachment sites of larvae with their initial contact sites on complex hard substrata was used to determine the role of larval exploration following initial contact Results indicated that, for Balanus sp. and $T$ crocea larvae, all 3 hypotheses were confirmed. Evidence of active behaviour was observed at the spatial scales considered in this study (entire panels and types of surfaces within panels), suggesting that active selection occurs at smaller and smaller scales. Balanus $\mathrm{sp}$. larvae were more abundant on panels which did not include the $1 \mathrm{~mm}$ scale of heterogeneity while at the level of types of surfaces within each panel, they settled preferentially in grooves of 1 and $10 \mathrm{~mm}$ This suggests that different factors affect the competent larvae at different spatial scales. For $T$. crocea the larvae selected the most complex type of panels and generally settled on the most exposed surfaces. Differences between initial larval contact sites and final attachment sites confirmed the benthic behaviour hypothesis.
\end{abstract}

KEY WORDS: Larval ecology · Substratum heterogeneity - Substratum complexity Micro-habitat selection Balanus. Tubularia

\section{INTRODUCTION}

Most temperate benthic invertebrates have a planktonic larval phase. For sessile organisms, this phase is important since it enables them to colonize new sites and maintain a wide geographical distribution. Larval dispersal and settlement can be controlled by passive (hydrodynamic) processes, or by active processes where larval behaviour plays an important role. These processes are not necessarily mutually exclusive (Boudreau et al. 1993). They may act over different spatio-temporal scales and their relative importance can

- Corresponding author

E-mail: edwin.bourget@girog.ulaval.ca vary among species, flow environments and according to the duration of the planktonic phase (Butman 1987).

It is generally accepted that passive processes dominate at large spatial scales and gradually give way to behavioural control of movement as the settlement site approaches (see review by Pawlik 1992). Boudreau et al. (1993) have recently proposed a conceptual model for the settlement of the lobster larvae Homarus americanus. They suggested that settlement involved a passive horizontal transport at large scales ( $\geq \mathrm{km}$ ) and an active selection of micro-habitats at smaller scales (stens of $\mathrm{m}$ ). In this model, the first contact with the substratum is due to an active process where postlarvae swim actively, responding to odor plumes (Boudreau et al. 1993). An analogous model was suggested for the intertidal barnacle Semibalanus balanoides 
(Bourget 1988) where larval settlement is divided into 2 phases. First, larval transport and contact with the substratum are under the control of water flow and turbulence. The second phase involves 3 active steps which have been described as broad exploration, fine exploration and inspection (Crisp 1961, 1974). A third model has been proposed by Butman \& Grassle (1992) that involves simultaneous action of passive and active processes in sediment selection of the infaunal polychaete Capitella sp. This model, which was supported by multiple-choice experiments in still water and flume flows (Grassle et al. 1992), proposed that larvae are swimming up and down, testing sediment on contact, while being transported by the flow.

The larvae could display 2 different types of active or passive behaviours depending on whether they are in the water column (planktonic behaviour) or on or near the substratum after the initial contact (benthic behaviour) At a spatial scale $\leq 1 \mathrm{~m}$, the planktonic behaviour refers mainly to the influence the larvae may or may not have on their position of initial contact with the substratum. By comparing the position of initial contact of larvae with those of inert particles, it would be possible to determine if the planktonic behaviour is predominantly a passive (controlled by hydrodynamics) or an active (controlled by behaviour) process at a short distance from the substratum. Active planktonic behaviour would be indicated if patterns of contact with the substratum differed from those observed with inert particles. In that case, larval site selection could be influenced by the heterogeneity (represented by holes or grooves), complexity (combination of holes or grooves of different depths) or some other factors linked to the physical or chemical (odor plumes) characteristics of the substratum (e.g. the hydrodynamic regime over its surface, its brightness, texture, etc.). In a previous study, Bourget et al. (1994) found that the topography of the substratum (scales of heterogeneity and complexity) had a strong influence on the small scale distribution of species but did not influence overall community characteristics (e.g. density, richness, abundance). Mechanisms by which heterogeneity might have influenced the distribution of these species were not, however, examined in detail.

Active exploratory behaviour and settlement preferences of larvae have been hypothesized to play an important role in determining the distribution of barnacle larvae on heterogeneous substrata (Crisp 1974, Bourget 1988, Chabot \& Bourget 1988, Le Tourneux \& Bourget 1988, Bourget et al. 1994) The importance of larval exploration of complex surfaces in determining small scale $(<\mathrm{cm})$ spatial patterns of settlement was examined for 2 species of the Beaufort, North Carolina, USA, benthic community, the barnacle Balanus amphi- trite and the bryozoan Bugula neritina (Walters 1992). Exploratory larval behaviour was found to be important at a small spatial scale ( $\mathrm{mm}$ to $\mathrm{cm}$ ).

In this study, we examine the relative importance of active and passive mechanisms in determining, at small. scales $(\mathrm{mm}, \mathrm{cm})$, the initial contact and final attachment sites of Balanus sp. and Tubularia crocea larvae. Here, the term larvae will be used loosely to designate the actinulae which are liberated by adults of Tubularia, but it should be kept in mind that they are juvenile polyps and not really true larvae (Hawes 1958). Specifically, we test 3 hypotheses: (1) larvae of Balanus sp. and $T$. crocea exhibit settlement preferences with respect to scales of topographic heterogeneity $(0,1,10$ and $100 \mathrm{~mm} \mathrm{~V}$-shaped grooves); (2) these preferences are modified by substratum complexity (combinations of scales of topographic heterogeneity; and (3) these preferences are mediated by larval behaviour directly on or near the substratum (benthic behaviour: after initial contact with the substratum).

\section{MATERIALS AND METHODS}

Our study was carried out near the pier of Pivers Island at the Duke University Marine Laboratory, Beaufort, North Carolina, USA $\left(34^{\circ} 43^{\prime} 03^{\prime \prime} \mathrm{N}, 76^{\circ} 40^{\prime} 18^{\prime \prime} \mathrm{W}\right)$. We used specially crafted artificial panels to control topography. The substrata consisted of $1 \mathrm{~cm}$ thick grey polyvinylchloride (PVC) panels measuring $150 \times$ $300 \mathrm{~mm}$ in plane view. Spatial heterogeneity was obtained by alternating grooves of equilateral sides and flat surfaces which led to different types of surfaces within each panel. Scale of heterogeneity and order of complexity refer to the lateral size of the $V$-shaped grooves $(0,1,10$ and $100 \mathrm{~mm})$ and the number of scales combined on each settlement panel, respectively (Bourget et al. 1994). Eight different types of settlement panels (A to $\mathrm{H}$ ) were constructed ranging from flat $(\mathrm{A})$ to highly complex $(\mathrm{H})$ panels which led to a total of 27 potential settlement types of surfaces (Fig. 1, Table 1).

Once contact has been established with the substratum, the larvae can actively reject the substratum, settle immediately at the site of initial contact or explore further near the contact site. A comparison between the patterns of initial contact and settlement sites would indicate whether settlement site 'selection' was active or passive. Differing patterns would indicate the presence of an active benthic behaviour in the larval selection of a settlement site. To determine the position of first contact with the substratum, series of panels ( $\mathrm{A}$ to $\mathrm{H}$ ) were treated with a thin layer of vacuum silicone grease (High-Vacuum Grease, Dow Corning, USA) to trap larvae encountering the panels (Walters 1992). Untreated series which allowed larvae to actively reject or explore 
Complexity of panels

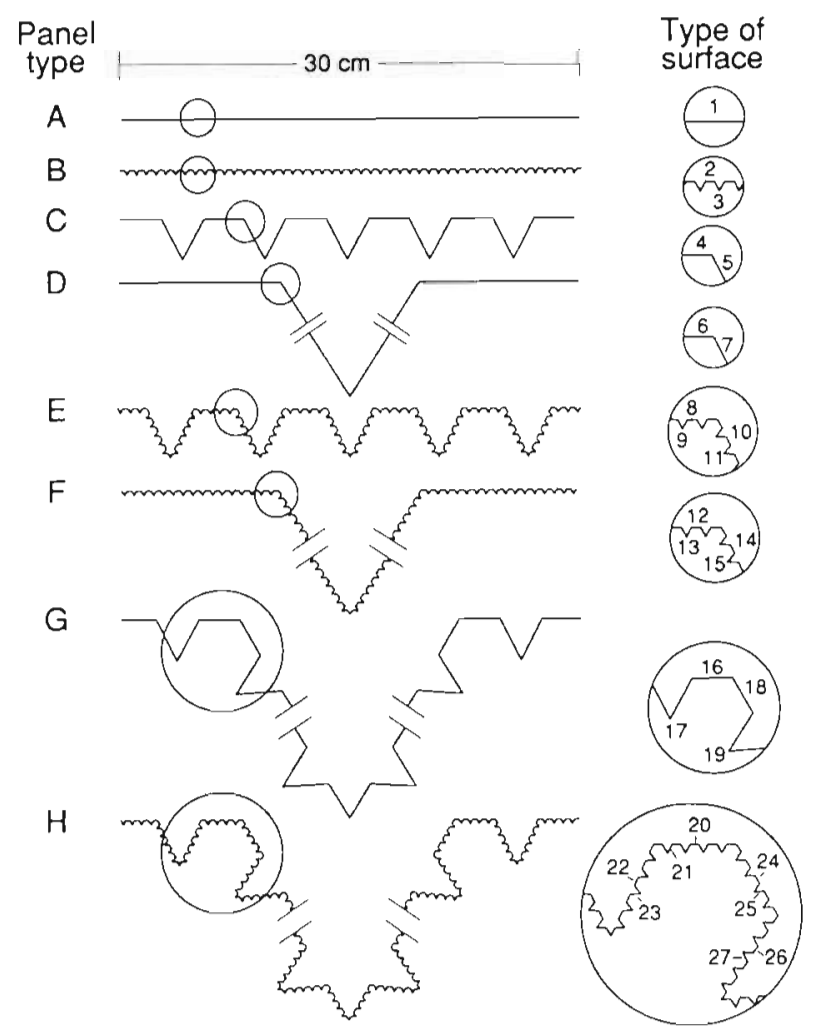

Fig. 1 Eight types of settlement panels (A to $H$ ) used for the experiments. Circles correspond to an enlargement of a portion of the panels and illustrate the different types of surfaces ( 1 to 27) within each panel. The figures are not drawn to scale (modified after Bourget et al. 1994). Although only a portion of the panels is enlarged, the number of settled larvae on the whole surfaces (1 to 27: e.g. top to bottom of crevasses) were considered for sampling

the substratum after initial contact were used to determine the final attachment site of larvae.

Larval settlement and initial contact sites. Three experiments, labelled hereafter I, II and III (2 blocks of 2 series of panels, 1 coated and 1 uncoated, per experiment) were carried out (Fig. 2). All experiments took place under a floating dock, $30 \mathrm{~cm}$ below the surface near the pier of the Duke University Marine Laboratory. Blocks were used to control spatial variability. In each experiment, the 16 panels within each block were randomly positioned in 2 parallel rows of 8 panels and oriented along the tidal axis. The experiments lasted $5 \mathrm{~d}(10$ semi-diurnal tidal cycles). At the end of each experiment, the exact position (type of surface, Fig 1) and density
A

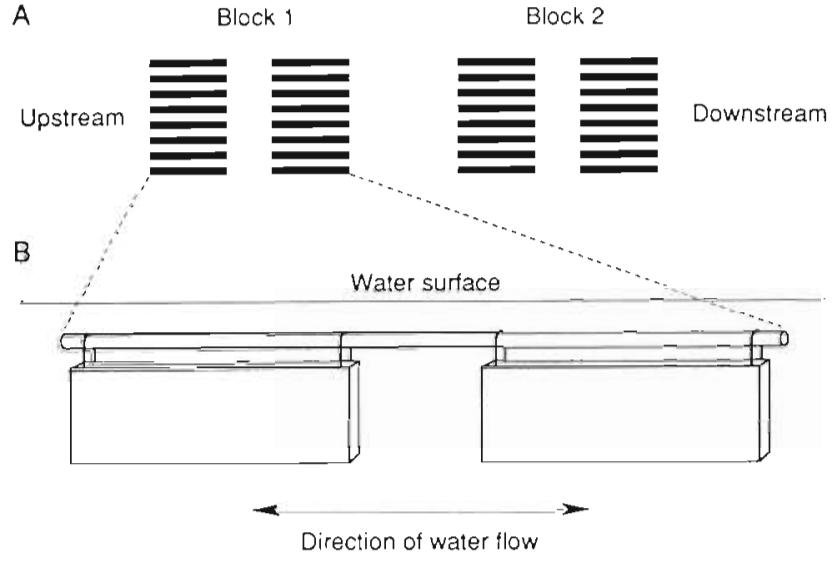

Fig. 2. (A) Schematic representation of the experimental design. (B) Enlarged panels and flow direction. For each experiment, panels (treated and untreated) were placed at random within each block. The experiment was repeated 3 times (I, Il and III). Since experimental conditions (e.g. number of larvae in the plankton, current velocity, etc.) may have been different among experiments, the results of each experiment were analyzed separately

(larvae $\mathrm{cm}^{-2}$ of available substratum) of all Balanus sp. and Tubularia crocea larvae on each settlement panel were determined under a dissecting microscope. To avoid potential border effects (Chabot \& Bourget $1988)$, only the central area $(100 \times 200 \mathrm{~mm}$ in plane view) of each panel was analyzed.

During all experiments, current velocity and orientation $\left(0\right.$ to $180^{\circ}$ axis corresponding to the upstreamdownstream position of panels), tidal amplitude and water temperature were recorded. Current measurements were obtained during the $3 \mathrm{rd}$ and 8 th semi-diurnal tidal cycles ( 2 periods of $12 \mathrm{~h}$ per experiment) with a Marsh-McBirney currentmeter placed at the depth of the panels (Table 2). Currents were within $20^{\circ}$ of the upstream-downstream axis and ranged from $2.27 \mathrm{~cm}$ $\mathrm{s}^{-1}$ during the flow to $8.60 \mathrm{~cm} \mathrm{~s}^{-1}$ at the ebb. Due to technical problems, no physical data were available for

Table 1. Topographical characteristics of each artificial panel used during the settlement site selection experiments

\begin{tabular}{|lccccc|}
\hline $\begin{array}{l}\text { Settlement } \\
\text { panel }\end{array}$ & $\begin{array}{c}\text { General } \\
\text { characteristic }\end{array}$ & $\begin{array}{c}\text { Scale(s) } \\
\text { of hetero- } \\
\text { geneity }(\mathrm{mm})\end{array}$ & $\begin{array}{c}\text { Order } \\
\text { of com- } \\
\text { plexity }\end{array}$ & $\begin{array}{c}\text { No. of } \\
\text { scales } \\
\text { combined }\end{array}$ & $\begin{array}{c}\text { No. of } \\
\text { types of } \\
\text { surfaces }\end{array}$ \\
\hline $\mathrm{A}$ & Homogeneous & 0 & 1 & 1 & 1 \\
$\mathrm{~B}$ & Heterogeneous & $0+1$ & 2 & 2 & 2 \\
$\mathrm{C}$ & Heterogeneous & $0+10$ & 2 & 2 & 2 \\
$\mathrm{D}$ & Heterogeneous & $0+100$ & 2 & 2 & 2 \\
$\mathrm{E}$ & Heterogeneous & $0+1+10$ & 3 & 3 & 4 \\
F & Heterogeneous & $0+1+100$ & 3 & 3 & 4 \\
$\mathrm{G}$ & Heterogeneous & $0+10+100$ & 3 & 3 & 4 \\
$\mathrm{H}$ & Heterogeneous & $0+1+10+100$ & 4 & 4 & 8 \\
\hline
\end{tabular}


Table 2. Mean current velocity, tidal amplitude and water temperature recorded during the experiments. The numbers between parentheses correspond to the orientation of currents and the standard error of tidal amplitude and water temperature

\begin{tabular}{|c|c|c|c|c|c|}
\hline \multirow[t]{2}{*}{ Exp } & \multirow{2}{*}{$\begin{array}{c}\text { Penod of } \\
\text { immersion } \\
\text { (1992) }\end{array}$} & \multicolumn{2}{|c|}{$\begin{array}{l}\text { Current velocity } \\
\left(\mathrm{cm} \mathrm{s}^{-1}\right)\end{array}$} & \multirow{2}{*}{$\begin{array}{l}\text { Tidal } \\
\text { amplitude } \\
(\mathrm{cm})\end{array}$} & \multirow{2}{*}{$\begin{array}{c}\text { Temperature } \\
\left({ }^{\circ} \mathrm{C}\right)\end{array}$} \\
\hline & & Low tide & High tide & & \\
\hline \multirow{2}{*}{ I } & $280 \mathrm{ct}$ & - & - & \multirow{2}{*}{$65.64(2.52)$} & \multirow{2}{*}{$18.91(0.06)$} \\
\hline & $02 \mathrm{Nov}$ & - & - & & \\
\hline \multirow{2}{*}{ II } & 10 Nov & $8.60\left(163.14^{\circ}\right)$ & $5.07\left(-5.41^{\circ}\right)$ & \multirow{2}{*}{$81.05(2.28)$} & \multirow{2}{*}{$15.38(0.13)$} \\
\hline & $15 \mathrm{Nov}$ & $7.65\left(161.97^{\circ}\right)$ & $3.74\left\{-4.64^{\circ}\right\}$ & & \\
\hline \multirow{2}{*}{ III } & $02 \mathrm{Dec}$ & $7.46\left(159.18^{\circ}\right)$ & $2.27\left(-0.07^{\circ}\right)$ & \multirow{2}{*}{$58.90(2.30)$} & \multirow{2}{*}{$11.89(0.13)$} \\
\hline & $07 \mathrm{Dec}$ & $8.54\left(156.04^{\circ}\right)$ & $2.70\left(-5.55^{\circ}\right)$ & & \\
\hline
\end{tabular}

effect of block $\left[b_{j} \sim N\left(0, \sigma_{b}{ }^{2}\right)\right]_{i} t_{j}$ is the effect of treatment $j, j=$ coated or uncoated $p_{k}$ is the effect of type of panel $k, k=\mathrm{A}, \mathrm{B}, \mathrm{C}, \ldots, \mathrm{H}_{\mathrm{i}} \mathrm{tp}_{, k}$ is the interaction between treatment and types of panels; $e_{y j k}$ is the random error component associated with the interpanel variation $\left[e_{l j k}-\mathrm{N}\left(0, \sigma_{e}{ }^{2}\right)\right] ; \mathrm{s}_{(k)}$ is the effect of types of surfaces within types of panels; $t_{l l(k)}$ is the interaction between treatment and types of surfaces within types of panels $\varepsilon_{i j k l}$ is the random error component associated with the intra-panel variation $\left[\varepsilon_{j j k}\right] \sim$ $\left.N\left(0, \sigma_{\varepsilon}^{2}\right)\right]$.

Further, we divided the total random error component with respect to the inter- and intra-panel variations.

Expt I. Nearby water temperature data (at. $2 \mathrm{~h}$ interval) were provided by Duke University Marine Laboratory (Table 2). Mean water temperatures were of $18.9,15.4$ and $11.9^{\circ} \mathrm{C}$ for Expts I, II and III respectively.

Statistical analysis. The effect of substratum heterogeneity on larval settlement was examined at 2 levels of observation: the level of the entire panel and the level of the types of surfaces within each type of panel. At the observation level of the entire panel, comparisons were made among densities observed between panels. At the observation level of the types of surfaces, density comparisons among surfaces were made within panels. To determine if larval settlement, after initial contact, was predominantly an active or a passive process, we compared the final attachment site of metamorphosed larvae with the position of initial contact. Active benthic selection would be indicated if these distributions differed. The distribution of larvae refers to the pattern of relative larval abundance and statistical differences between densities of larvae observed on the various types of panels or types of surfaces within each type of panel.

Nested ANOVAs with crossed factors (without replication) in a completely randomized block design were used to examine the effect of treatment (coated or uncoated), types of panels (A to $H$ ) and types of surfaces (1 to 27) within panels on the density of Balanus sp. and Tubularia crocea larvae. Since the statistical models used were unusual, they are presented hereafter. The linear statistical model used for the above analysis had the following form:

$\mathrm{y}_{i j k l}=\mu+\mathrm{b}_{1}+\mathrm{t}_{j}+\mathrm{p}_{k}+\mathrm{t} \mathrm{p}_{j k}+\mathrm{e}_{\jmath \jmath k}+\mathrm{s}_{l(k)}+\mathrm{ts}_{j \ell k \mid}+\varepsilon_{i j k l}$

where $y_{i j k}$ is the observation of the response variable on the lth type of surface associated to the panel of type $k$ of the $j$ th treatment and $i$ th block; $\mu$ is the overall mean of the response variable; $b_{i}$ is the random
Thus, the appropriate error term to test the effect of treatment, types of panels and the interaction between treatment and types of panels was $\mathrm{e}_{i j k}$, the random error component associated with the inter-panel variation. The random error component associated with the intra-panel variation, $\varepsilon_{\eta j k}$, was used to test the effect of types of surfaces within types of panels and the interaction between treatment and types of surfaces.

A square root transformation of the response variable (density) was used to stabilize the variance among treatments. Homoscedasticity was confirmed by graphical examination of the residuals (Montgomery 1991). The normality assumption was verified with a Shapiro and Wilk's test (Zar 1984) at the level of significance $\alpha=0.01$.

Nested ANOVAs in a completely randomized block design were used to examine the effect of complexity on the densities of Balanus sp. and Tubularia crocea larvae. The linear statistical model used for this type of analysis had the following form:

$$
Y_{i j k}=\mu+b_{1}+c_{j}+p_{k(j)}+e_{j j k}
$$

where $y_{j k}$ is the observation of the response variable on type of panel $k$ associated with the complexity $j$ of block $i_{i} c_{j}$ is the effect of complexity $j_{j} j=1,2,3,4 ; \mathrm{p}_{k(y)}$ is the effect of type of panel $k$ within the complexity $j$.

The effect of complexity and types of panels within complexity was tested with $e_{i j k}$ and no transformation of the data was carried out since the assumptions of homoscedasticity and normality were respected.

For both types of analysis of variance, an a posteriori multiple comparisons test, using least square means (SAS 1989), was applied when a factor was found to be significant $(p<0.05)$. These comparisons were done at a corrected level of significance, $\alpha / c$, where $c$ is the total number of pairwise comparisons and $\alpha=0.05$. Thus, the maximum error rate under any complete or partial null hypothesis was less than $\alpha$. 
Table 3. Balanus sp. and Tubularia crocea. Nested ANOVAs with crossed factors showing the effect of types of panels, types of surfaces and treatment (coated or uncoated) on the density of larvae for each experiment. (I. II and III). See 'Methods' for the meaning of the error terms. $e_{i j k}$ : Block $\times$ Treatment + Block $\times$ Panels + Block $\times$ Treatment $\times$ Panels; $\varepsilon_{\eta k k}$ : Block $\times$ Surfaces $($ panels $)$ + Block $\times$ Treatment $\times$ Surfaces(panels). ${ }^{\prime} p<0.05, \cdots p<0.01, \cdots p<0.001$, ns: nonsignificant $(p>0.05)$

\begin{tabular}{|c|c|c|c|c|c|c|c|}
\hline \multirow{2}{*}{$\begin{array}{l}\text { Sources } \\
\text { of variation }\end{array}$} & \multirow[t]{2}{*}{ df } & \multicolumn{2}{|c|}{ Expt I } & \multicolumn{2}{|c|}{ Expt II } & \multicolumn{2}{|c|}{ Expt III } \\
\hline & & MS & $F$ & MS & $F$ & MS & $F$ \\
\hline \multicolumn{8}{|l|}{ Balanus sp. } \\
\hline Block & 1 & 0.000 & & 0.001 & & 0.010 & \\
\hline Treatment & 1 & 1.831 & $238.54 \cdots$ & 3.018 & $1227.43^{\cdots}$ & 0.348 & $80.40^{\cdots}$ \\
\hline Panels & 7 & 0.180 & $23.48^{\cdots}$ & 0.217 & $88.30^{\cdots}$ & 0.010 & $2.29^{\text {ns }}$ \\
\hline Treat $\times$ Panels & 7 & 0.041 & $5.30^{\cdots}$ & 0.044 & $17.83 \cdots$ & 0.015 & $3.57^{\circ}$ \\
\hline $\mathrm{e}_{i j k}$ & 15 & 0.008 & & 0.002 & & 0.004 & \\
\hline Surfaces (panels) & 19 & 0.026 & $4.44^{\cdots} \cdots$ & 0.019 & $6.87 \cdots$ & 0.007 & $2.22^{\circ}$ \\
\hline Treat $\times$ Surf(panels) & 19 & 0.016 & $2.70^{\cdots}$ & 0.023 & $8.11 \cdots$ & 0.004 & $1.37^{05}$ \\
\hline$\varepsilon_{i j k l}$ & 38 & 0.006 & & 0.003 & & 0.003 & \\
\hline Total & 107 & & & & & & \\
\hline \multicolumn{8}{|l|}{ Tubularia crocea } \\
\hline Block & 1 & 0.018 & & 0.000 & & 0.043 & \\
\hline Treatment & 1 & 0.032 & $1.75^{\mathrm{ns}}$ & 0.079 & $4.05^{n s}$ & 0.000 & $0.02^{\text {ns }}$ \\
\hline Panels & 7 & 0.011 & $0.58^{\mathrm{ns}}$ & 0.023 & $1.20^{\mathrm{ns}}$ & 0.108 & $6.09 \cdot$ \\
\hline Treat $\times$ Panels & 7 & 0.003 & $0.18^{\mathrm{ns}}$ & 0.027 & $1.40^{\mathrm{ns}}$ & 0.068 & $3.87^{\circ}$ \\
\hline $\mathrm{e}_{2 j k}$ & 15 & 0.018 & & 0.020 & & 0.018 & \\
\hline Surfaces (panels) & 19 & 0.005 & $1.11^{\mathrm{ns}}$ & 0.004 & $1.31^{\mathrm{ns}}$ & 0.064 & $11.66^{\circ} \cdots$ \\
\hline Treat $\times$ Surf(panels) & 19 & 0.003 & $0.79^{n s}$ & 0.003 & $0.95^{\mathrm{ns}}$ & 0.020 & $3.60 \cdots$ \\
\hline$\varepsilon_{i j k j}$ & 38 & 0.004 & & 0.003 & & 0.006 & \\
\hline Total & 107 & & & & & & \\
\hline
\end{tabular}

\section{RESULTS}

\section{Settlement sites versus initial contact sites}

Results of the ANOVAs differed substantially for the 2 taxa, Balanus sp. and Tubularia crocea (Table 3). For Balanus sp., there were significant effects of treatment, types of panels (except in Expt III), types of surfaces within panels and significant interactions of treatment $x$ types of panels and treatment $x$ types of surfaces (except in Expt III) on the density of larvae. For $T$. crocea, the ANOVA showed no influence of treatment in the experiments. Types of panels and types of surfaces influenced significantly the density of larvae in Expt III only, but $T$ crocea spat density was low in experiments I and II. In Expt III, the interactions treatment $x$ types of panels and treatment $x$ types of surfaces within panels were significant. As an indication, the mean number of larvae per block ( 2 series of 8 panels) were 969, 1195 and 102 for Balanus sp. and 70 , 59 and 298 for $T$ crocea for I, II and III respectively.

\section{Species specific responses at the entire panel level}

At the scale of the panels, Balanus sp. larvae were more abundant on panels which did not include $1 \mathrm{~mm}$ grooves (A, C, D and G) while Tubularia crocea larvae settled on the most complex panels (H). Multiple comparisons tests, taking into account significant interactions, showed different patterns of Balanus sp. larval distribution on treated and untreated panels, as well as among experiments (I, II and III) (Table 4). Nonetheless, Table 4 shows that the patterns of relative abun-

Table 4. Balanus sp. and Tubularia crocea. Multiple comparisons of larvae density among types of panels for each treatment. Panel types are placed by decreasing order of density. Nonsignificant differences among panel types are underlined

\begin{tabular}{|c|c|c|}
\hline Expt & Treatment & $\begin{array}{c}\text { Bonferroni's multiple } \\
\text { comparisons test } \\
\text { (types of panels) }\end{array}$ \\
\hline \multicolumn{3}{|c|}{ Balanus sp. } \\
\hline \multirow{2}{*}{ I } & Treated & $A C G D E B H F$ \\
\hline & Untreated & $A C D G B E F H$ \\
\hline \multirow{2}{*}{ II } & Treated & $A C D G F B H E$ \\
\hline & Untreated & $A D C G B F H E$ \\
\hline \multirow{2}{*}{ III } & Treated & $A D G C B E F H$ \\
\hline & Untreated & A HCFBEDG \\
\hline \multicolumn{3}{|c|}{ T. crocea } \\
\hline \multirow{2}{*}{ III } & Treated & $\mathrm{GEHBFDCA}$ \\
\hline & Untreated & $\underline{\mathrm{H}} \mathrm{GFECDBA}$ \\
\hline
\end{tabular}




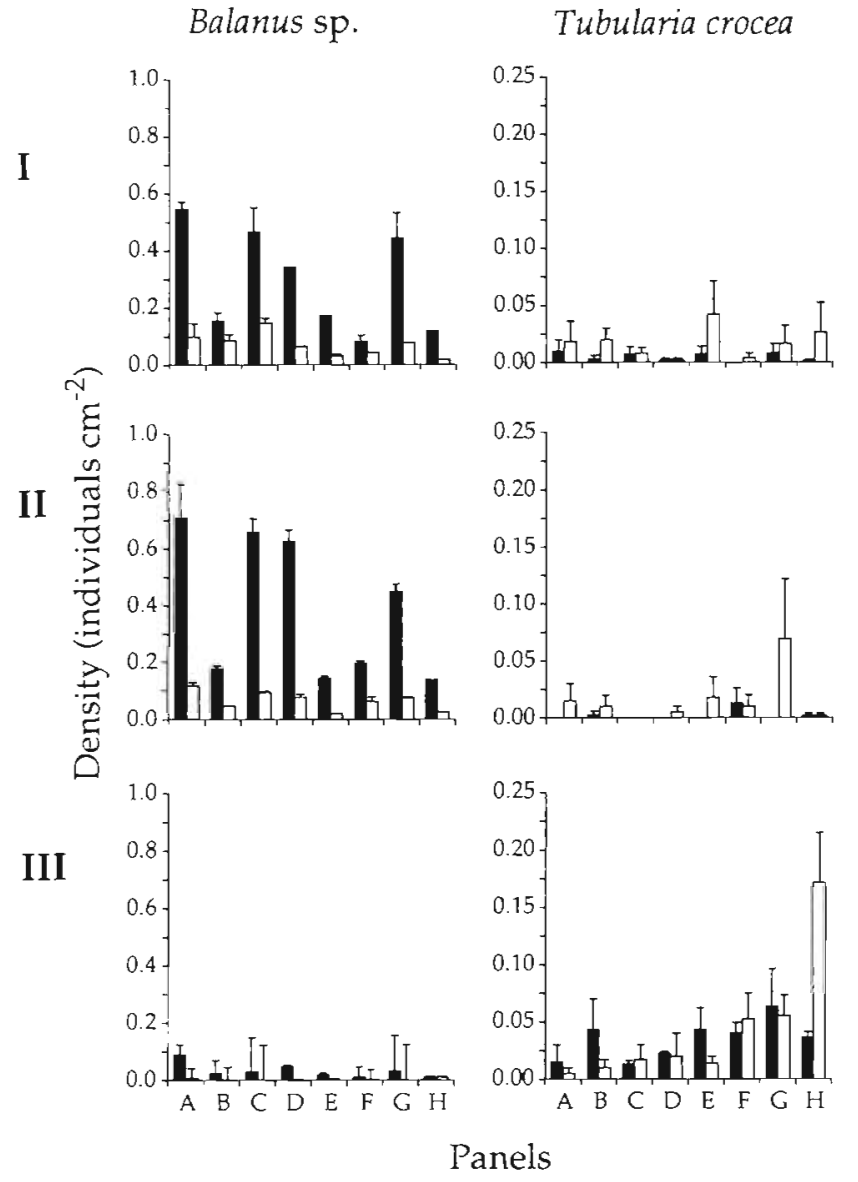

Fig. 3. Balanus sp and Tubularia crocea. Mean density of larvae on treated (solid bars) and untreated (open bars) panels during Expts I, II and III. Vertical bars represent the standard error dance among types of panels, as indicated by the decreasing order of density of larvae on treated and untreated panels, were consistent in all experiments; except in Expt III where densities were much lower than in the other experiments (Fig. 3). There was a definite tendency for larval abundance to be lower on panels which included $1 \mathrm{~mm}$ grooves ( $\mathrm{B}, \mathrm{E}, \mathrm{F}$ and $\mathrm{H}$ ) than on other panels (Table 4, Fig 3). Treatment effects for $T$ crocea were limited to 1 panel in 1 experiment only (III) (Table 4) due to the low numbers of $T$ crocea larvae in Expts I and II (Fig. 3).

\section{Species specific responses at the types of suriaces level}

Within the treated panels of the 2nd order of complexity ( $B, C$ and D), with 1 exception ( $C$ of Expt II), there were no significant differences in the densities of Balanus sp. among types of surfaces (Table 5). On untreated panels, however, the density of larvae in grooves $(1,10$ and $100 \mathrm{~mm})$ was either equal or greater than on adjacent exposed surfaces. Hence, the distribution of settled larvae on panels B (1 mm) and C $(10 \mathrm{~mm})$ compared to their initial encounter with a panel suggests some movement after initial contact.

On the more complex panels, those with 3 scales of heterogeneity ( $E, F$ and $G$ ), the treated panels led to relatively similar patterns of distribution among types of surfaces between experiments (Expts I and II) (Table 5). The untreated panels, however, led to patterns of distribution either similar (E) or totally different ( $F$ and $G$ ) from those of the treated ones. In general, Balanus sp. larvae settled more abundantly in grooves of 1 and $10 \mathrm{~mm}$ than on adjacent flat surfaces

Table 5. Balanus sp. and Tubularia crocea. Multiple comparisons of larvae density among types of surfaces within panels for each treatment. Types of surfaces are placed in decreasing order of density (treated: vacuum silicone grease coated; untreated: not coated with vacuum silicone grease). Nonsignificant differences among surface types are underlined

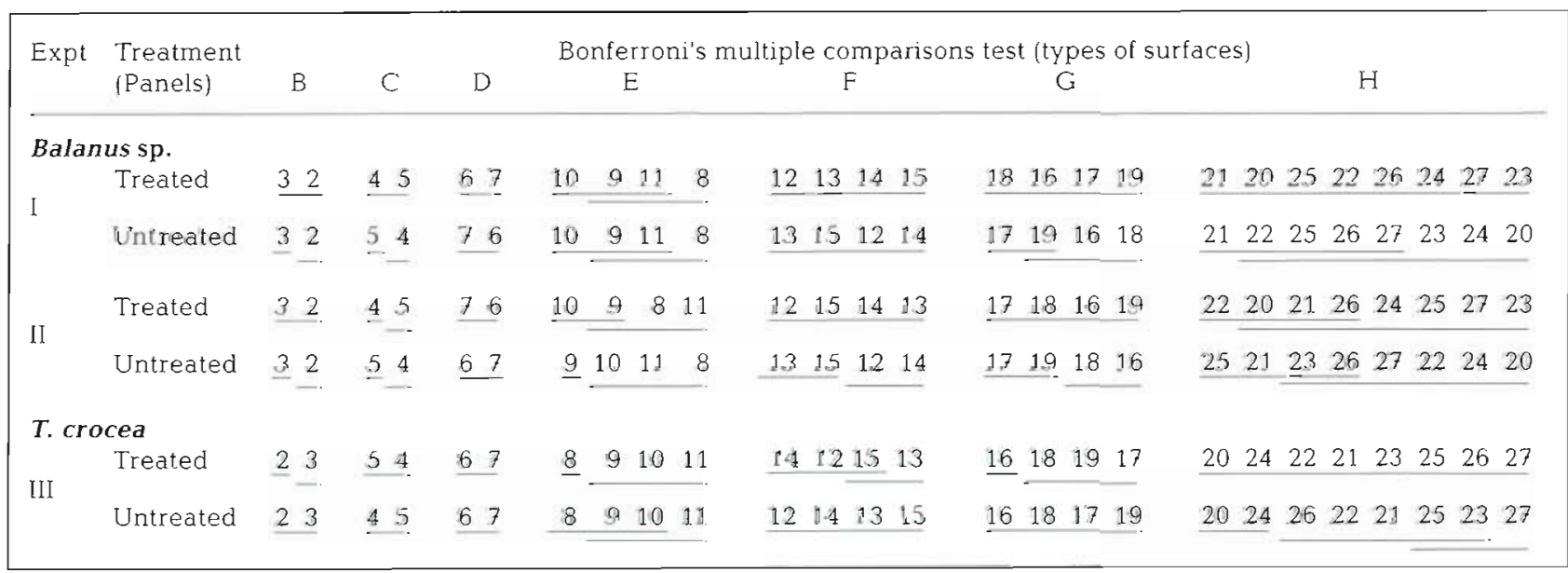


Table 6. Balanus sp. Results of nested ANOVAs showing the effect of levels of complexity and types of panels within level of complexity on the density of larvae on treated and untreated panels for Expts $I$ and II. $p<0.05, \cdots p<0.01, \cdots p<0.001$, ns: nonsignificant $(p>0.05)$

\begin{tabular}{|lrrrrrr|}
\hline \multirow{2}{*}{$\begin{array}{l}\text { Sources } \\
\text { of variation }\end{array}$} & df & \multicolumn{2}{c}{ Expt l } & \multicolumn{2}{c|}{ Expt ll } \\
& & MS & $F$ & MS & $F$ \\
\hline Treated panels & & & & & \\
Block & 1 & 0.0003 & $0.06^{\text {ns }}$ & 0.0017 & $0.35^{\text {ns }}$ \\
Complexity & 3 & 0.0720 & $14.76^{\cdots}$ & 0.1615 & $32.74 \cdots$ \\
Panels (complexity) & 4 & 0.0612 & $12.52 \cdots$ & 0.0989 & $20.06 \cdots$ \\
Error & 7 & 0.0049 & & 0.0049 & \\
Total & 15 & & & & \\
Untreated panels & & & & & \\
Block & 1 & 0.0018 & $2.83^{\text {ns }}$ & 0.0000 & $0.41^{\text {ns }}$ \\
Complexity & 3 & 0.0047 & $7.38^{\bullet}$ & 0.0033 & $19.84 \cdots$ \\
Panels (complexity) & 4 & 0.0023 & $3.68^{\text {ns }}$ & 0.0014 & $8.56 \cdots$ \\
Error & 7 & 0.0006 & & 0.0002 & \\
Total & 15 & & & & \\
& & & & & \\
\hline
\end{tabular}

while they were evenly distributed among types of surfaces at the $100 \mathrm{~mm}$ scale of heterogeneity. This was evident on the untreated panels $F$ and $G$, although clear significant differences were found for Expt II only. For the more complex panels $(\mathrm{H})$, similar patterns of relative densities were observed among treatments, but again, the patterns of distribution observed for untreated panels were different from those of treated ones. A slight tendency for densities to be higher in grooves of untreated panels $H$ was observed in Expt II.

For each type of panel, Tubularia crocea larvae able to explore the substratum were more abundant on the most exposed surfaces. The pattern was analogous to that observed on panels measuring the first contact with the substratum. Within panels, however, the abundances on each type of surfaces differed between treated and untreated substrata. Indeed, on the simpler types of panels (B, C and D), significant differences in $T$. crocea densities among types of surfaces were observed only on treated panels $B$, those with the 1 mm grooves (Table 5). For the panels of the 3 rd order of complexity ( $E, F$ and $G$ ), in spite of statistical differences in patterns of larval distribution (Table 5), treated and untreated panels exhibited relatively similar decreasing order of density among types of surfaces on a given type of panel. On treated and untreated panels of the 2nd and 3rd order of complexity, $T$. crocea larvae were generally more abundant on exposed surfaces, but not always significantly so. For the most complex panels $(\mathrm{H})$, while no significant differences among types of surfaces were observed on treated panels, the larvae free to explore the substratum (untreated paneis) settled pretentially on the most exposed surfaces (20 and 24) and least in $1 \mathrm{~mm}$ grooves located within $10 \mathrm{~mm}$ grooves.

\section{Species specific responses to complexity}

The density of Balanus sp. larvae decreased with complexity and, for complex panels of the same order of complexity, tended to be lower on panels which included the $1 \mathrm{~mm}$ scale of heterogeneity. Significant effects of complexity on the density of Balanus sp. larvae were observed for both experiments (I and II) and treatments (coated and uncoated) (Table 6). Types of surfaces within given levels of complexity also had a significant effect, except for untreated panels of Expt I. The densities generally decreased with increasing complexity for treated and untreated panels (Fig. 4). Multiple comparisons tests showed different patterns of distribution among experiments and treatments. However, densities were consistently lower on panels of the 4 th order of complexity (panels $\mathrm{H}$ ), compared to panels of the 1 st order (panels A), but no significant differences of density were found between panels of the $3 \mathrm{rd}$ ( $E, F$ and $G$ ) and 4 th order of complexity (Fig. 4).

The effect of complexity on the density of Tubularia crocea larvae was totally different from that observed for Balanus sp. larvae. The nested ANOVAs revealed a significant effect of complexity for untreated panels only (Table 7). Further, no significant effect of types of panels within complexity was observed and that independent of treatment. On untreated panels, the densities of larvae decreased with decreasing complexity. Multiple comparisons showed significantly higher

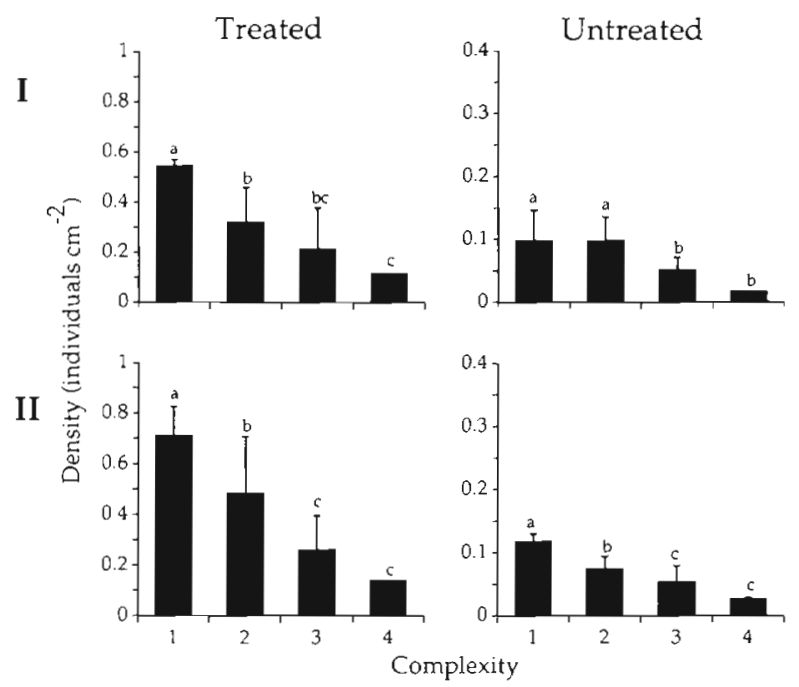

Fig. 4. Least square mean density of Balanus sp. larvae in relation to complexity for trcutcud und untreated pañels of Expis I and II. Vertical bars correspond to the standard error. Identical letters represent densities which did not differ significantly (level of complexity 1: panel A; 2 : B, C, D; 3: E, F, G; 4:H) 
Table 7. Tubularia crocea. Results of nested ANOVAs showing the effect of levels of complexity and types of panels within level of complexity on the density of larvae on treated and untreated panels for Expt III. $" p<0.05, \cdots p<0.01, \cdots p<$ 0.001 , ns: nonsignificant $(p>0.05)$

\begin{tabular}{|c|c|c|c|}
\hline \multirow{2}{*}{$\begin{array}{l}\text { Sources } \\
\text { of variation }\end{array}$} & \multirow[t]{2}{*}{ df } & \multicolumn{2}{|c|}{ Expt III } \\
\hline & & MS & $F$ \\
\hline \multicolumn{4}{|l|}{ Treated panels } \\
\hline Block & 1 & 0.0000 & $0.02^{\mathrm{ns}}$ \\
\hline Complexity & 3 & 0.0008 & $1.12^{\mathrm{ns}}$ \\
\hline Panels (complexity) & 4 & 0.0004 & $0.55^{\mathrm{ns}}$ \\
\hline Error & 7 & 0.0007 & \\
\hline Total & 15 & & \\
\hline \multicolumn{4}{|l|}{ Untreated panels } \\
\hline Block & 1 & 0.0020 & $2.81^{\text {ns }}$ \\
\hline Complexity & 3 & 0.0134 & $18.92 *$ \\
\hline Panels (complexity) & 4 & 0.0005 & $0.75^{\mathrm{ns}}$ \\
\hline Error & 7 & 0.0007 & \\
\hline Total & 15 & & \\
\hline
\end{tabular}

densities on panels of the 4 th order of complexity (panels H) than on other types of panels (Fig. 5).

\section{DISCUSSION}

\section{Final attachment sites versus substratum heterogeneity and complexity}

Species diversity has been reported to increase with environmental complexity (Simpson 1964) and to be higher on heterogeneous surfaces than on homogeneous ones (Woodin 1978, Menge et al. 1985). Few studies, however, have separated the effects of substratum heterogeneity and complexity on the abundance of sessile invertebrates (Menge et al. 1985, Bourget et al. 1994). During early colonization, substratum heterogeneity and complexity were observed to have very little effect on the overall percentage cover of an epibenthic community in Passamaquoddy Bay, New Brunswick, Canada (Bourget et al. 1994). Similarly, overall density of sessile invertebrates of the southern shores of Taboguilla Island (Panama) did not differ between homogeneous and heterogeneous substrata (Menge et al. 1985). In both studies, however, substratum heterogeneity had an impact on the distribution of species. The percentage cover of hydrozoans of the Taboguilla Island, for example, was significantly higher on heterogeneous surfaces while the density of the barnacle Chthamalus was significantly higher on homogeneous surfaces.

In our study, the density of Balanus sp. larvae was higher on panels which did not include $1 \mathrm{~mm}$ grooves and also decreased with increasing panel complexity. For Tubularia crocea larvae, the density was signifi-

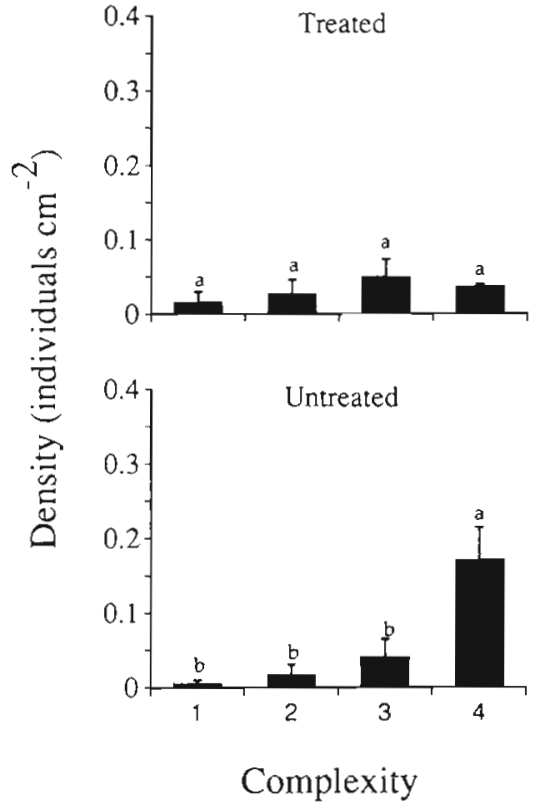

Fig. 5. Tubularia crocea. Least square mean density of larvae in relation to complexity for treated and untreated panels of Expt III. Vertical bars correspond to the standard error. Identical letters represent densities which did not differ significantly (level of complexity 1: panel $A_{i} 2: B, C, D ; 3: E, F, G ; 4: H$ )

cantly higher on the mast complex panels (H) than on others. Cyprids are known to settle preferentially on smooth, fast-flowing surfaces whereas others prefer a greater rugosity and turbulent conditions (Mullineaux \& Butman 1991). It is difficult to compare our results with those of others because definitions and measures of substratum heterogeneity and complexity differ from one study to another. In the study of Menge et al. (1985), for example, substratum heterogeneity was represented by holes and defined as the within-site variation using 4 indices of heterogeneity: the propor tion of heterogeneous surface, the average hole depth, the variability in hole depth and an overall index Thus, an increase in the overall index of heterogeneity defined by Menge et al. (1985) would be more or less equivalent to an increase of overall complexity in our study (at the scale of the panels) because it involves the combination of holes of different depths. If this were the case, our results would agree with those of Menge et al. (1985) for the barnacle and the hydrozoans.

Although there is no general consensus on the definitions of substratum heterogeneity and complexity, the effects of surface contour and small scale heterogeneity on the settlement of some sessile invertebrate larvae is well documented. Cypris larvae have been reported to settle more abundantly in grooves than on adjacent flat surfaces (Crisp \& Barnes 1954, Crisp 1974, Bergeron \& Bourget 1986, Chabot \& Bourget 1988) and to metamorphose more frequently around the bases of 
bumps (Walters 1992). Despite the fact that larval density of Balanus sp. was higher on panels which did not include $1 \mathrm{~mm}$ grooves, the density of Balanus sp. larvae was significantly higher in grooves of simple panels $B$ and $C$ ( 1 and $10 \mathrm{~mm}$ scales of heterogeneity), thus conforming to the expected pattern. For the more complex panels ( $E, F, G$ and $H$ ), densities were also generally higher in grooves than on adjacent flat surfaces although these differences were not always significant.

For the hydroids Obelia longissima and Tubularia larynx, Bourget et al. (1994) observed no significant differences in percentage cover between types of surfaces which included grooves and flat surfaces, but Mullineaux \& Garland (1993) observed that Tubularia crocea settled on small scale topographic highs due to its preferences for regions of high turbulence and strong shear stress. For T. crocea larvae, densities were higher on the most exposed surfaces of complex panels, but again, significant differences were found on panels $F$ and $H$ only. The patterns of relative densities observed in our study seem to confirm predictions of Mullineaux \& Garland (1993) for the settlement positions of $T$. crocea. The rareness of clear statistical differences between the density on the exposed flat surfaces and other types of surfaces within each type of panel tend to support the idea that hydrozoans are non-discriminatory organisms (Scheltema 1974) or less capable of selecting particular scales of heterogeneity as suggested by Bourget et al. (1994).

\section{Settlement site selection (active vs passive processes)}

\section{Planktonic behaviour}

Passive processes have been reported to control the initial contact of larvae with the substratum in several studies on the settlement of sessile invertebrate larvae (Mullineaux \& Butman 1991, Armonies \& HellwigArmonies 1992, Harvey et al. 1995) and infaunal polychaetes (Hannan 1984, Butman 1989, Butman \& Grassle 1992, Grassle et al. 1992). Several approaches have been used to investigate the role of passive processes in larval settlement. Some studies involved sediment traps with different sampling characteristics (Hannan 1984, Butman 1989) or laboratory flumes allowing direct observations of larvae (Mullineaux \& Butman 1991, Butman \& Grassle 1992, Grassle et al. 1992). Others involved the comparison of the initial contact sites predicted by the hydrodynamic regimes with the observed initial contact positions of larvae (Armonies \& Hellwig-Armonies 1992) or their final attachment sites (Mullineaux \& Garland 1993). Harvey et al. (1995) compared the relative abundance of inert particles on 3-dimensional structures of different complexity and diameter with the relative abundance of semi-mobile bivalve spat on the same structures. Their results suggested that the meso-scale $(10 \mathrm{~cm})$ distribution patterns of 4 species of bivalves could be explained by passive processes only. The method used by Harvey et al. (1995) would not, however, enable us to discriminate between active near-bottom planktonic and benthic behaviours in cases where the distribution patterns of inert particles differed from the distribution patterns of larvae. Our approach comparing the initial contact sites to the settlement sites of larvae allows us to isolate the effect of post-contact dispersal prior to attachment. Further, by comparing the initial contact position of larvae on panels to those of inert particles under laboratory conditions (see 'Results' in companion paper by Grégoire et al. 1996), it is possible to verify the likelihood of small scale differences due to larval behaviour near the substratum, though admittedly, differences in patterns between field and laboratory results could happen for other reasons.

We compared the initial contact sites of Balanus sp. and Tubularia crocea larvae observed in the field with the contact sites of graded inert particles obtained in a laboratory flume (see companion paper). For instance, at the level of the entire panel, densities of inert particles were consistently higher on panels $A$ and $B$ and lower on panels $G$ and $H$ (Table 3 of Grégoire et al. 1996). Decreasing order of densities and the groups formed by multiple comparisons tests were also different from those observed for Balanus sp, and $T$ crocea larvae on treated panels.

On the simpler panels ( $B, C$ and $D)$, densities of inert particles were higher in grooves (type of surface number 3 ) of panels $B$ and on flat surfaces of panels $C$ and $D$ (types of surfaces number 4 and 6 respectively) than on other surfaces on the panels (Table 3 of Grégoire et al. 1996). Inert particles were generally more abundant on the exposed types of surfaces of the more complex panels $(E, F, G$ and $H$, i.e. types of surfaces number 8 , $13,16,20$ and 21). Again, patterns of distribution of inert particles among types of surfaces were different than those observed for Balanus sp. larvae on treated panels. However, the decreasing orders of density observed on simple panels ( $B, C$ and D) were similar for inert particles and barnacle larvae while they were different for panels of the 3rd and 4 th orders of complexity ( $E, F, G$ and $H)$.

The patterns of distribution of Tubularia crocea larvae were also different than patterns of distribution of inert particles and the relative abundances were similar for panels D, E and H. In summary, different patterns of distribution among types of surfaces were observed for inert particles and larvae which suggests some form of active selection at a short distance from 
the substratum. Further, the decreasing orders of density of inert particles and Balanus sp. larvae were similar on simple panels ( $B, C$ and $D)$ while the densities of inert particles and $T$ crocea larvae were generally higher on the most exposed surfaces of complex panels.

These results could be due to an active selection by Balanus and Tubularia larvae at a short distance from the substratum. Further, the observed differences in the small scale (types of surfaces) patterns of relative densities of larvae and inert particles tend to confirm our conclusions, but further small scale work on larval behaviour needs to be carried out before a firm conclusion can be reached.

\section{Benthic behaviour}

By comparing the position of initial contact with the final attachment sites of the barnacle Balanus amphtrite and the bryozoan Bugula neritina larvae, Walters (1992) found that larval exploration of substratum was important in determining the patterns of settlement of these species on complex hard substrata (Lego toy building block baseplates). Both species metamorphosed more frequently around the bases of bumps than would be predicted from the distribution of initial surface contact. At the same study site and at both levels of observation (types of panels and types of surfaces), our results also revealed different patterns of distribution of initial contact and final attachment sites for Balanus sp. and Tubularia crocea larvae suggesting that larvae explore the substratum prior to attachment. Some authors have suggested that the selection of a settlement site on heterogeneous substrata may be directly dependent on a tactile response to the topography of the surface (Crisp \& Barnes 1954) or indirectly influenced by other factors directly or indirectly associated to substratum heterogeneity. These include the food availability (Crisp 1974), the hydrodynamic regime over the substratum (Mullineaux \& Butman 1991, Mullineaux \& Garland 1993), the presence of refuges from predators (Crisp 1974, Menge et al. 1985) and disturbances or competition (Woodin 1978). The results presented here suggest that the barnacle Balanus sp. and the hydrozoan $T$ crocea larvae would be capable of an active planktonic behaviour at a short distance from the substratum and of an active benthic behaviour after initial contact.

At the entire panel level of observation, the results (Table 4) suggest that Balanus sp. larvae preferred types of panels which did not contain $1 \mathrm{~mm}$ grooves. The differing patterns of distribution observed for inert particles and Balanus sp. larvae added to the similarity of the patterns of decreasing order of larvae density between treated and untreated panels (although patterns of distribution were different) suggest that the selection at the entire panel level would mainly be due to an active planktonic behaviour Considering types of surfaces, the larvae preferentially selected grooves of 1 and $10 \mathrm{~mm}$. This result is analogous to that found by Wethey (1986) for Semibalanus balanoides, which settled preferentially next to bumps about $1 \mathrm{~mm}$ in height. The absence of significant differences of densities between grooves and flat surfaces of panels D indicate that the exploration of Balanus sp. larvae after initial contact could be limited to distances smaller than $100 \mathrm{~mm}$. Crisp \& Barnes (1954) observed a diminution in the ratio of the number of larvae on flat surfaces to the number of larvae in grooves as the grooves were drawn closer together Their experiments with spaced grooves also showed a diminution in the number of Elminius modestus larvae on flat surfaces up to $1 \mathrm{~cm}$ from the edge of a groove. They suggested that if pits or grooves were placed less than $5 \mathrm{~mm}$ apart the cypris larvae would be able to find them by exploration while these sites may not be accessible to all the migrating larvae if they were placed farther from one another. The hydrozoan $\mathrm{Tu}$ bularia crocea preferentially selected the most complex panels. At the types of surfaces level of observation, the larvae of Tubularia seem to prefer the most exposed surfaces of simple and complex panels. No differences in densities were observed, however, on treated and untreated panels $\mathrm{D}$ which indicate that the exploration of $T$. crocea larvae could also be limited to scales smaller than $100 \mathrm{~mm}$.

The method used here may give us some indications on the distance Balanus sp. and Tubularia crocea larvae can actively explore the substratum after initial contact. It cannot, however, give us information on the distance from the substratum where the larvae could begin to actively and significantly control their movement. Thus erroneous conclusions could be reached if the distance at which the larvae began to show significant active planktonic behaviour was smaller than the scale of resolution of the factor considered (e.g conspecifics, brightness, topographical heterogeneity, etc.).

Acknowledgements. We thank L. Lapointe for her assistance in the field and Dr D. Rittschof of Duke University Marine Laboratory for allowing us to use his raft and laboratory space for the field work. Thanks are also due to Dr Kirby-Smith of the Natural History Resource Center, Duke University Manne Laboratory, who provided the temperature data. We are grateful to Drs M. Claereboudt, M. Harvey and G. Miron for their helpful comments. This article is a contribution to the program of GIROQ (Groupe interuniversıtaire de recherches oceanographiques du Québec). This research was supported by NSERC and FCAR grants to E.B. M.L. was supported by a NSERC scholarship during the course of this work. G. Daigle assisted with the statistical analysis and validated every test. 


\section{LITERATURE CITED}

Armonies W. Hellwig-Armonies M (1992) Passive settlement of Macoma balthica spat on tidal flats of the Wadden Sea and subsequent migration of juveniles. Neth $\mathrm{J}$ Sea Res 29:371-378

Bergeron P, Bourget E (1986) Shore topography and spatial partitioning of crevice refuges by sessile epibenthos in an ice disturbed environment. Mar Ecol Prog Ser 28:129-145

Boudreau B, Bourget E, Simard Y (1993) Behavioural responses of competent lobster postlarvae to odor plumes. Mar Biol 117:63-69

Bourget E (1988) Barnacle larval settlement: the perception of cues at different spatial scales. In: Chelazzı $G$, Vannini $M$ (eds) Behavioral adaptation to intertidal infe. Plenum Press, New York, p 153-172

Bourget E, DeGuise J, Daigle G (1994) Scales of substratum heterogeneity, structural complexity and the early establishment of a marine epibenthic community. J Exp Mar Biol Ecol 181:31-51

Butman CA (1987) Larval settlement of soft-sediment invertebrates: the spatial scales of pattern explained by actuve habitat selection and the emerging role of hydrodynamical processes. Oceanogr Mar Biol Ann Rev 25:113-165

Butman CA (1989) Sediment-trap experiments on the importance of hydrodynamical processes in distributing settling invertebrate larvae in near-bottom waters. J Exp Mar Biol Ecol 134:37-88

Butman CA, Grassle JP (1992) Active habitat selection by Capitella sp. I larvae. I. Two-choice experiments in still water and flume flows. J Mar Res 50:669-715

Chabot R, Bourget E (1988) Influence of substratum heterogeneity and settled barnacle density on the settlement of cypris larvae. Mar Biol 97:45-56

Crisp DJ (1961) Territorial behaviour in barnacle settlement. J Exp Biol 38:429-446

Crisp DJ (1974) Factors influencing the settlement of marine invertebrate larvae. In: Grant PT, Mackie AM (eds) Chemoreception in marine organisms. Academic Press, London, p $177-265$

Cnsp DJ, Barnes H (1954) The orientation and distribution of barnacles at settlement with particular reference to surface contour. J Anim Ecol 23:142-162

Grassle JP, Butman CA, Mills SW (1992) Active habitat selection by Capitella sp. larvae. II. Multiple-choice experiments in still water and flume flows J Mar Res 50: $717-743$

This article was submitted to the editor
Grégoire Y, Bourget E, Verrette JL (1996) Depositıon of mimics of planktonic invertebrate larvae on simple and complex substrata in flume flows. Mar Ecol Prog Ser 135: $89-100$

Hannan, CA (1984) Planktonic larvae may act as passive particles in a turbulent near-bottom flow. Limnol Oceanogr 29:1108-1116

Harvey, M, Bourget, E, Ingram, RG (1995) Experimental evidence of passive accumulation of marine bivalves on filamentous epibenthic structures. Limnol Oceanogr 40:91-104

Hawes, FB (1958) Preliminary observations on the settlement. of the actinula larva of the Tubularia Iarynx (Ellis \& Solander). A Mag Nat Hist 13:147-155

Le Tourneux, F, Bourget, E (1988) lmportance of physical and biological settlement cues used at different spatial scales by the larvae of Semibalanus balanordes. Mar Biol 97 $57-66$

Menge, BA, Lubchenco, J, Ashkenas, LR (1985) Diversity, heterogeneity and consumer pressure in a tropical rocky intertidal community. Oecologia 65:394-405

Montgomery, DC (1991) Design and analysis of experiments, 3rd edn. John Wiley \& Sons, New York.

Mullineaux, LS, Butman, CA (1991) Initial contact, exploration and attachment of barnacle (Balanus amphitrite) cyprids settling in flow. Mar Biol 110:93-103

Mullineaux, LS, Garland, ED (1993) Larval recruitment in response to manipulated field flows. Mar Biol 116:667-683

Pawlik, JE (1992) Chemical ecology of the settlement of benthic marine invertebrates. Oceanogr Mar Biol Ann Rev 30: $273-335$

SAS Institute Inc (1989) SAS/STAT User's Guide, Version 6 , 4 th edn. SAS Institute, Cary NC

Scheltema, RS (1974) Brological interactions determining larval settlement of marıne invertebrates. Thalassia Jugosl 10:263-296

Simpson, GG (1964) Species density of North American recent mammals. Syst Zool 13:57-73

Walters, LJ (1992) Field settlement locations on subtidal marine hard substrata: is active larval exploration involved? Limnol Oceanogr 37:1101-1107

Wethey, D (1986) Ranking of settlement cues by barnacle larvae: influence of surface contour. Bull Mar Sci 39:393-400

Woodin, SA (1978) Refuges, disturbance and community structure: a marine soft-bottom example. Ecology 59: $274-284$

Zar, JH (1984) Biostatistical analysis, 2nd edn. Prentice-Hall, Englewood Cliffs

Manuscript first received: September 15, 1994

Revised version accepted: August 28, 1995 